\title{
Nuevas culturas asociativas en un contexto de cambio social. Análisis de la evolución del tejido asociativo inmigrante en Galicia (2006-2016)
}

\author{
Iria Vázquez Silva
}

Universidade da Coruña. Grupo de Estudios Territoriales (GET)

ivazquez@udc.es

\section{Antía Pérez-Caramés}

Universidade da Coruña. Equipo de Sociología de las Migraciones Internacionales (ESOMI) antia.perez@udc.es

\section{Silvia Mosquera Mirás}

Equipo de ONGD Ecos do Sur silvia.m.miras@gmail.com

\section{Resumen}

El objetivo principal de este artículo es realizar un estudio longitudinal del tejido asociativo inmigrante en Galicia a lo largo de la última década. Partiendo de un registro previo de 2006, hemos actualizado el censo de asociaciones en 2016 con el fin de analizar su evolución. En concreto, examinaremos la pervivencia y la transformación del escenario asociativo, así como los factores que han permitido el mantenimiento, el cese y/o la creación de ciertas asociaciones en un contexto de cambio.

Los resultados indican una alta volatilidad en el panorama asociativo, así como una diversificación de su perfil, composición por país de origen y orientación. Detrás de esta transformación encontramos diversos factores que la propician. En primer lugar, hay que tener en cuenta el cambio de ciclo migratorio en España: reducción de la inmigración y aumento de reemigración y retorno. En segundo lugar, la pérdida de carácter prioritario de la inmigración en la agenda pública y la reducción de fondos económicos para la integración. Por último, han sido claves las diferencias en la cultura participativa en el país de origen para la creación de nuevas asociaciones.

La metodología utilizada es una combinación de técnicas cuantitativas (explotación de datos de censos y registros de asociaciones levantados en 2006 y 2016, análisis sociodemográfico de flujos y stock migratorio y cuestionario telefónico a asociaciones) y cualitativas (entrevistas semiestructuradas a miembros de asociaciones e informantes clave).

Palabras clave: asociacionismo migrante; ciclo migratorio; participación política; experiencia asociativa; Galicia 
Abstract. New associative cultures in a context of social change: An analysis of the evolution of the immigrant associative network in Galicia (2006-2016)

The main aim of this article is to conduct a longitudinal analysis of the immigrant associative network in Galicia over the last decade. Starting from a previous record of 2006, we updated the census of associations in 2016 in order to analyze their evolution. Specifically, we examine the continuity and the transformation in the associative scene, as well as the factors that contribute to the maintenance, dissolution and/or creation of certain associations within a context of change. The results point to a high volatility in the associative panorama, as well as a diversification of the profile, composition by country of origin and orientation of the associations. A variety of factors are behind this transformation. Firstly, the change in the migration cycle in Spain - a reduction in its immigration and an increase in re-emigration and return. Secondly, the loss of the primary status of immigration in the public agenda and the reduction in economic funding for integration. Finally, differences in the involvement culture in the country of origin are shown to be key for the creation of new associations. The methodology used combines quantitative (use of data from censuses and association registers in 2006 and 2016, a socio-demographic analysis of migration flows and stocks and a telephone questionnaire for associations) and qualitative techniques (semi-structured interviews of association members and key informants).

Keywords: migrant associations; migration cycle; political involvement; associative experience; Galicia

\section{Sumario}

\begin{tabular}{|c|c|}
\hline \multirow{3}{*}{$\begin{array}{r}\text { 1. Introducción } \\
\text { 2. Los estudios sobre asociacionismo } \\
\text { migrante: De la explicación del } \\
\text { dinamismo asociativo a la propuesta de } \\
\text { tipologías analíticas }\end{array}$} & \multirow{2}{*}{$\begin{array}{l}\text { 4. Del boom a la fragmentación. } \\
\text { El panorama asociativo inmigrante } \\
\text { en Galicia entre } 2006 \text { y } 2016\end{array}$} \\
\hline & \\
\hline & \multirow{2}{*}{$\begin{array}{l}\text { 5. La transformación del tejido asociativo } \\
\text { inmigrante. Alta volatilidad y atención a } \\
\text { la exclusión social }\end{array}$} \\
\hline \multirow{3}{*}{$\begin{array}{l}\text { 3. El cambio de ciclo migratorio en } \\
\text { Galicia. Las llegadas se reducen, pero } \\
\text { aumenta el retorno y la reemigración }\end{array}$} & \\
\hline & 6. Conclusiones \\
\hline & Referencias bibliográficas \\
\hline
\end{tabular}

\section{Introducción}

El paso de una década (2006-2016) ha dejado huella en el número y en el tipo de asociaciones inmigrantes en Galicia. No podemos obviar que han sido años de crisis económica y de cambios importantes en la agenda política. Asimismo, como veremos, también ha habido un cambio relevante en el propio ciclo migratorio de la sociedad gallega.

Lo cierto es que la entrada de nuevas variables en juego a lo largo de esta década ha modificado sustancialmente el panorama asociativo inmigrante en Galicia, lo que ha provocado el desarrollo de un cambio muy brusco que, junto a otros factores, puede ayudarnos a comprender el panorama actual. A lo largo de este artículo nos detendremos en estos cambios, avanzando también 
en las diversas causas que pueden explicar dichas transformaciones en el tejido asociativo inmigrante en Galicia.

En este artículo se comparan los resultados de dos investigaciones sobre asociacionismo migrante en Galicia que se llevaron a cabo con diez años de distancia (2006 y 2016), lo que permite comparar el panorama asociativo en el momento álgido de la llegada de inmigrantes y, una década después, con la recesión económica instalada y el cambio de ciclo migratorio iniciado. No obstante, es preciso hacer aquí una serie de matizaciones respecto de la metodología empleada para levantar ambos censos de entidades para que se comprenda el potencial y las limitaciones de este análisis comparado.

El censo del año 2006 fue realizado en el marco de la investigación Asociacionismo e integración social de las inmigrantes en Galicia, financiada por el Servizo Galego de Igualdade de la Xunta de Galicia (Vázquez Silva, 2006) y, para su elaboración se partió del listado de asociaciones de inmigrantes y emigrantes retornados que recogía el portal Galicia $\mathrm{Aberta}^{1}$, elaborado por la Secretaría Xeral de Emigración de la Xunta de Galicia con el objeto de registrar a las organizaciones susceptibles de solicitar subvenciones a diversas convocatorias al respecto. El trabajo de campo para esta investigación, basado en entrevistas semidirigidas, permitió depurar y completar este censo inicial. El censo que levantamos en el año 2016 para la investigación Asociacionismo migrante en Galicia. Lazos transnacionales y codesarrollo desde una perspectiva de género ${ }^{2}$ partió de cuatro registros: el del portal Galicia Aberta, sin actualizar a medida que las convocatorias de subvenciones se iban suprimiendo; el censo elaborado para la investigación de 2006; el registro general de asociaciones de la Xunta de Galicia ${ }^{3}$, y, por último, el listado de asociaciones de inmigrantes elaborado en el marco del proyecto Entre Nós ${ }^{4}$, un programa de intervención social en el ámbito del codesarrollo realizado por la ONGD Ecos do Sur que tenía como principal objetivo el fortalecimiento del tejido asociativo inmigrante. Dada la necesidad de depurar los resultados obtenidos mediante la agregación de regis-

1. Puede consultarse en el siguiente enlace: http://emigracion.xunta.gal/

2. PR815 A 2014-23, financiado por la Dirección Xeral de Relacións Exteriores e coa UE de la Xunta de Galicia.

3. Se trata de un registro general de asociaciones, regulado por la Ley Orgánica 1/2002, de 22 de marzo, reguladora del Derecho de Asociación, así como por el Real Decreto 949/2015, de 23 de octubre, por el que se aprueba el Reglamento del Registro Nacional de Asociaciones. Dado que el registro autonómico incorpora diversas categorías en función de la actividad declarada, se ha consultado y depurado la información para las siguientes: inmigración, minorías étnicas, contra el racismo y la xenofobia, de ayuda al inmigrante, asistenciales, culturales y otras asociaciones. El registro puede consultarse en el siguiente enlace: http:// www.xunta.es/rexistros/RexistroRAS.htm

El principal escollo que presenta dicho registro es que no existe un protocolo para su revisión y actualización, por lo que, de acuerdo con la información proporcionada por una técnica a cargo de este registro, entrevistada en el marco del trabajo de campo para este proyecto, son excepcionales los casos en que una asociación decide tramitar su baja, dada la innecesariedad percibida del trámite y el trabajo de gestión que este implica.

4. Puede consultarse más información sobre este proyecto en el siguiente enlace: http://www. ecosdosur.org/entrenos.html 
tros, se realizó un rastreo y un cuestionario telefónico que permitieron obtener el listado final de entidades. Consideramos que es necesario precisar aquí que resulta complicado decidir hasta qué punto una asociación se puede considerar como clausurada a pesar de no tener actividad declarada, ni financiación, ni apenas socios o socias, porque, en el transcurso del trabajo de campo, hemos visto cómo entidades que se encontraban en esta situación podían reactivarse si en una comunidad surgían nuevos intereses y/o nuevas personas motivadas para retomar su actividad, aprovechando que la asociación ya estaba registrada y contaba con personalidad jurídica propia.

En lo que respecta a las principales variables de clasificación, para el censo de 2006 se dispone de las siguientes: distribución provincial y municipal y composición por lugares de procedencia (deducida a partir del nombre de la entidad). Mediante el trabajo de campo se ha obtenido información adicional para 28 de las 55 asociaciones censadas: número de personas asociadas por sexo; número de mujeres presidentas y en las directivas, y principales actividades que se realizan. En el caso del censo de 2016, las variables de clasificación que derivan de la comparación, armonización y depuración de los registros son las siguientes: distribución provincial y municipal, composición por lugares de procedencia (empleando el mismo criterio que para el censo de 2006) y año de registro (que, en cierto modo, podemos interpretar como el año de constitución de la asociación). El cuestionario telefónico realizado a 30 de las 79 asociaciones censadas permite obtener información de un número significativo de variables adicionales 5 .

Como se deduce de las líneas precedentes, la comparación de ambos censos es limitada pero posible. Para las variables de distribución territorial y composición por nacionalidad, partimos del total del universo asociativo en ambos casos, pero para el resto de variables que analizaremos, conviene tener en cuenta que derivan de dos metodologías diferentes (entrevistas semidirigidas para 2006 y cuestionario telefónico para 2016) y que no se buscó una representatividad estadística en el número de asociaciones contactadas.

La investigación de 2016 incorpora también entrevistas semidirigidas a miembros de asociaciones migrantes y a informantes clave, que forman parte del material de análisis para la elaboración de este artículo.

La estructura que seguiremos comienza con unos breves apuntes teóricos que sintetizan y enmarcan las principales contribuciones en torno a la participación política de las comunidades migrantes a través de la forma asociativa, haciendo un especial énfasis en aquellas publicaciones que analizan el contexto español más reciente, marcado por la recesión económica. A continuación, presentamos un análisis sociodemográfico de la evolución reciente de los flujos y de los inventarios migratorios para pasar a abordar después el análisis de la evolución del tejido asociativo migrante gallego en dos apartados que sintetizan las evidencias encontradas a partir del estudio del material empírico

5. Puede consultarse el cuestionario empleado en la investigación en el siguiente enlace: https:// drive.google.com/open?id=1 mkk2pzL21JL8ag75cPcksT85rVfm1FbR9NOEFEsPQ28 
recogido en el proceso de investigación. El artículo cierra con unas breves conclusiones.

\section{Los estudios sobre asociacionismo migrante: De la explicación del dinamismo asociativo a la propuesta de tipologías analíticas}

Las asociaciones que las personas inmigrantes forman en los países de destino han sido actores privilegiados en los estudios sobre participación política de las comunidades migrantes. En primer término, la condición de no ciudadanía de muchas personas migrantes hace que sean este tipo de formas políticas prácticamente las únicas a través de las que pueden vehicular su incidencia en la esfera pública de los países de acogida, tal y como indican Aboussi et al. (2013: 91): «[...] el asociacionismo inmigrante es respuesta a una exclusión institucional del migrante, tanto por parte del país de origen como en el país de recepción». De ahí que, siguiendo a Aparicio (2011: 11), la primera etapa de investigaciones sobre asociacionismo migrante, que se corresponde temporalmente con el período que oscila entre mediados de los noventa y comienzos del siglo XXI, se centra en una orientación de corte más sociológico y en análisis más bien descriptivos, con vistas a capturar abundante información sobre un fenómeno aún incipiente. En este sentido, abundan los estudios de menor alcance geográfico (autonómico, provincial y local), como también aquellos que analizan el perfil, los objetivos, el modelo organizativo, los recursos y el tipo de actividades que desarrollan las asociaciones.

En segundo lugar, la importante actividad transnacional de estas entidades en pro de sus comunidades de origen ha implicado su consideración como agentes de codesarrollo, pero también la implicación con la situación de las personas inmigradas ha suscitado el debate en torno a su influencia en los procesos de integración de la población migrante; debate, este último, que se ha ordenado entre quienes consideran que las asociaciones de migrantes perjudican el proceso de integración porque suponen un cierto enclaustramiento étnico y quienes argumentan que sus actividades a favor de la participación social y política suponen un avance en la integración política de las comunidades migrantes (Lacomba y Giner, 2013). Estos debates se enmarcan en la segunda etapa en los estudios sobre asociacionismo migrante que identifica Aparicio (2011), en la que, tal y como apuntan Cebolla-Boado y López-Sala (2015), destacan tres temáticas en la literatura académica: los trabajos que estudian el papel de las asociaciones de inmigrantes como agentes de integración, las investigaciones en torno al liderazgo en las asociaciones y, finalmente, el análisis de los motivos $\mathrm{y}$ de los incentivos que llevan a las personas inmigrantes a asociarse.

En este apartado revisaremos principalmente las contribuciones que, a caballo entre ambas épocas en el estudio del asociacionismo migrante, han intentado explicar los factores que explican tanto el surgimiento de las asociaciones como sus características y formas organizativas, así como el mayor o menor dinamismo asociativo de unas y otras comunidades, ya que nos permite enlazar con las temáticas directamente abordadas en este artículo. 
En lo que respecta a las investigaciones sobre los factores que impulsan la participación de las personas migrantes a través de asociaciones y el diferente dinamismo asociativo entre las comunidades migrantes, el debate se ha centrado en identificar elementos favorecedores entre las características de la población inmigrante, pero también en apuntar al papel promotor que ejercen las administraciones públicas en su búsqueda de actores con los que interactuar para la elaboración y la implementación de políticas (Aguilar y Buraschi, 2013: 44), especialmente en lo que respecta a las administraciones locales y sus relaciones con estas entidades (Vermeulen, 2005). Es decir, habría una fuerza endógena en la emergencia asociativa pero las asociaciones también pueden tener un cierto carácter inducido. Por último, estaría el elemento sociodemográfico, esto es, la relación con la antigüedad de los flujos, ya que autores y autoras como Aparicio y Tornos (2010) apuntan a la mayor densidad asociativa entre los colectivos más antiguos en la inmigración a España.

En cuanto a la primera de las motivaciones, la que reside en la propia comunidad migrante, Moraes et al. (2013) consideran que existen dos explicaciones para el hecho de que las personas migrantes se organicen en función de su pertenencia nacional. Por una parte, está el elemento de la estructura de oportunidades y también de los obstáculos para la organización, que favorecen la asociación con los coétnicos y las coétnicas, y, por otra, la fortaleza que puede suponer la organización en torno a una misma comunidad, tanto en términos de impacto en dicha comunidad como de posibilidades de expandir los derechos en el ámbito cívico-político. A estas dos explicaciones, las autoras suman el elemento de la experiencia política y asociativa en el país de origen, así como el ya mencionado factor sociodemográfico.

Frente a estas explicaciones, en su amplio trabajo sobre las formas organizativas de las comunidades migrantes, Moya (2005: 839) indica que «el estímulo principal para la actividad asociativa no deriva del trasfondo cultural de los emigrantes, ni de los hábitos cívicos de sus huéspedes, sino de una fuente mucho más universal: el propio proceso migratorio». Estima, pues, que, antes que explicaciones de corte cultural (ya sea de la cultura de origen o de la del país receptor), son más bien necesidades insatisfechas por otras entidades (públicas o del tercer sector) las que actúan como detonantes del dinamismo asociativo. De hecho, en su investigación comparada sobre asociaciones de inmigrantes en España e Italia, Danese (2001: 87-8), explica la debilidad del tejido asociativo migrante en función de la dependencia que ambos Estados tienen del tercer sector para la cobertura de los derechos sociales, así como de la falta de autonomía de las asociaciones y al hecho de que su ámbito de actuación, en competencia con las entidades autóctonas del tercer sector, se ve restringido al mantenimiento de la cultura de origen y a la prestación de servicios para sus compatriotas. A este elemento primordial, Moya (2005: 853) suma el factor sociodemográfico, tanto en lo relativo al tamaño de la comunidad como a su diversidad interna y a las características de su proceso migratorio, tales como la antigüedad y la selectividad de los flujos por sexo y edad. Ambos 
factores producen una tendencia hacia la diversificación, la especialización y la completitud en el tejido asociativo.

En lo relativo a la propuesta de tipologías que sinteticen la diversidad de formas organizativas migrantes, Mora (2011) las ordena en función de su finalidad. Por una parte, estarían las socioculturales, que se centran en el mantenimiento de la identidad cultural; por otra, las de carácter asistencial, orientadas a la provisión de servicios y de ayuda a sus miembros, y, por otra, las reivindicativas, organizadas en torno a la reivindicación de derechos.

Zapata-Barrero (2004: 148) traza una correlación entre el tipo de tareas que realizan las asociaciones y la fase del ciclo migratorio en que se encuentra el contexto de acogida. Por tanto, según este autor existen tres fases migratorias que van a afectar al tipo de actividades a las que se orientan las asociaciones:

1. Primera fase: tareas de asistencia, asesoramiento y enseñanza de la lengua autóctona.

2. Segunda fase: cuando la residencia ya es permanente, se incorporan nuevos intereses como el de la justicia social en general, la demanda de derechos plenos y la igualdad de oportunidades, así como la defensa de sus identidades culturales.

3. Tercera fase: cuando las asociaciones de inmigrantes desempeñan un papel político determinante que incide en el proceso mismo de la multiculturalidad.

Otros trabajos, como el de Morell (2005), caracterizan a las asociaciones de migrantes a partir de su posición en el cruce de dos variables: su orientación prioritaria hacia el país de destino o hacia el país de origen y el carácter de las actividades que desarrollan (culturales, sociales o políticas).

Los trabajos más recientes en torno al asociacionismo migrante se han enfocado a analizar las debilidades del tejido asociativo en el actual contexto de crisis. Así, Aguilar y Buraschi (2013: 45) indican que el tránsito de lo que denominan «boom asociacionista» al período actual, marcado por la recesión y los recortes, ha supuesto un "proceso de progresiva institucionalización burocrática (y con frecuencia clientelar) de las entidades más grandes, así como el surgimiento y la aparición de asociaciones creadas expresamente para obtener subvenciones públicas. A este proceso también apuntan Moncusí et al. (2013), quienes indican que la instrumentalización política, principalmente por parte de las administraciones locales, es uno de los factores explicativos de la fragmentación y la «inercia asociativa» en el tejido de las organizaciones migrantes. En el contexto de esta nueva orientación investigadora se enmarca la interesante contribución de Lacomba y Giner (2013), que se preguntan por los motivos de la no implicación de las personas inmigrantes en las asociaciones.

En suma, elementos endógenos, como las culturas políticas en origen y destino, pero también exógenos, como el papel de las administraciones públicas y la cadencia de los flujos migratorios, explican el mayor o menor dinamismo asociativo y las características del tejido asociativo inmigrante, como veremos a continuación para el caso gallego. 


\section{El cambio de ciclo migratorio en Galicia. Las llegadas se reducen, pero aumenta el retorno y la reemigración}

El año 2008 marca la entrada de España en situación de recesión económica y también supone el inicio del fin de la década prodigiosa de la inmigración (Arango, 2010: 54). Así, si los primeros años del siglo XXI se habían caracterizado por unos flujos de inmigración cuantiosos que alcanzaron su punto álgido en el año 2007, a partir de este momento los volúmenes de llegadas se reducen considerablemente y comienza a aumentar la magnitud de los flujos de emigración, llevando al saldo migratorio a valores que apenas contribuyen al crecimiento demográfico (Reher et al., 2011).

Podemos resumir los principales elementos que caracterizan a este cambio de ciclo en una reducción de las nuevas llegadas, así como en un aumento de la emigración, tanto en la forma de retorno de residentes extranjeros, como de reemigración y emigración autóctona (López-Sala y Oso, 2015). Este fenómeno ha despertado un gran interés por parte de la comunidad académica nucleada en los estudios migratorios en España (Aja et al., 2012; Domingo et al., 2014; Cachón, 2014; Domingo y Blanes, 2015), aunque contamos, por el momento, con un menor número de estudios que hayan abordado cómo se ha producido este cambio de ciclo en Galicia. Entre estos, Oso y Martínez (2018) indican que el impacto de la crisis en los nichos de empleo en los que se inserta la población inmigrante ha sido más tardío en Galicia, razón por la que algunas otras autoras (Fernández, 2018) señalan que la inversión del saldo migratorio a números negativos y la apertura de una etapa caracterizada por la emigración de personas autóctonas e inmigrantes no se abre hasta el año 2011. Domingo y Blanes (2018) comentan, por su parte, que la intensidad de la emigración gallega actual es superior a la media de la población española. A partir de estas contribuciones reconstruiremos, en los siguientes párrafos, la evolución reciente de los flujos y de los saldos migratorios en la Galicia reciente, con el objeto de identificar tendencias y procesos que relacionaremos en el siguiente apartado con los cambios observados en el número, el perfil y la composición de las asociaciones de migrantes.

En el año 2007, Galicia contaba con una población extranjera de 81.442 personas, un $3 \%$ sobre el total de residentes, y con unas 178.841 personas no nacidas en España, lo que representaba algo más de un $6 \%$ de sus habitantes ${ }^{6}$. Esta diferencia es atribuible a las personas que, tras unos años de residencia, adquieren la nacionalidad española y abandonan por tanto el registro de la extranjería, pero también a la huella de la emigración gallega, ya sea transatlántica o europea, que, bajo la forma del retorno de segundas y hasta terceras generaciones, nutre la estadística de no nativos y no nativas. En la misma fecha estas proporciones eran del $10 \%$ y del $12 \%$ para España, lo que es indicativo de la menor capacidad de atracción migratoria que Galicia ha tenido durante el

6. La información de este apartado procede de la Estadística del Padrón Continuo a 1 de enero de 2007 y de 2016 (Instituto Nacional de Estadística). 
Gráfico 1. Flujos de inmigración, emigración y saldos migratorios de Galicia con el extranjero, 2002-2015

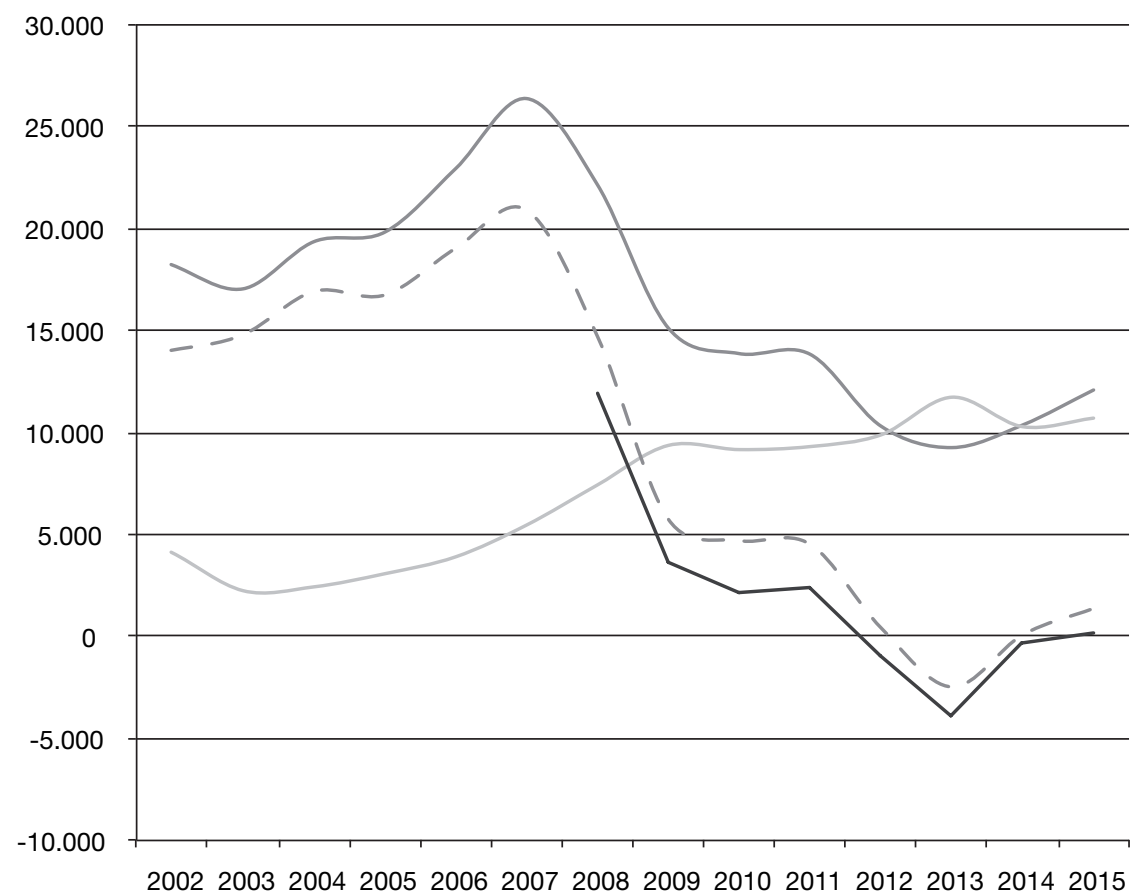

— Inmigración — Emigración - Saldo migratorio EVR — Saldo migratorio EM

Fuentes: elaboración propia en base a la Estadística de Variaciones Residenciales (varios años) y la Estadística de Migraciones (varios años, el dato para 2015 tiene carácter provisional). Instituto Nacional de Estadística.

boom de la llegada de inmigrantes. Casi una década después, la población gallega pierde algo más de 50.000 habitantes, aunque la extranjera crece levemente hasta alcanzar las 87.616 personas (un aumento del 7,6\%) y la población no nativa aumenta en 33.000 personas (un 19\%).

Sin embargo, en el subsuelo del firme del saldo actual los cambios han sido notables. La evolución de los flujos migratorios entre 2002 y 2015, fechas para las que tenemos información completa de entradas y salidas, nos muestra que las tendencias de ambas corrientes sufren un proceso de inversión en sus magnitudes antes y durante la crisis que lleva al saldo migratorio (con independencia de la fuente que utilicemos, ya sea la Estadística de Variaciones Residenciales o la Estadística de Migraciones) a valores negativos que solo parecen revertirse débilmente en nuestro último año de observación (2015). No obstante, y tal y como muestra el gráfico 1, la caída en los flujos de inmigración ha sido de mayor calado que el aumento de las emigraciones, que, durante los años de la 
crisis (2008-2015), arrojan un patrón relativamente estable con un ritmo de emigración media anual próximo a las 10.000 personas ${ }^{7}$.

Así, la tendencia que parece asentarse en los últimos tres años en lo que respecta a los flujos migratorios es la de una cierta estabilización en el volumen de entradas y salidas, de una magnitud semejante y en torno a 10.000 , que lleva a que las migraciones apenas contribuyan al crecimiento demográfico y, de hacerlo, sea restando habitantes.

Y bien, ¿cuáles han sido los cambios en estos últimos años en lo que respecta a la composición de la población inmigrante que reside en Galicia? En la siguiente sección analizaremos por tanto la distribución de la población nacida en el extranjero de acuerdo con las principales comunidades de origen y sexo, así como su distribución en el territorio gallego, con el fin de identificar sus características fundamentales en el momento actual.

\subsection{Características sociodemográficas principales de la población inmigrante residente en Galicia}

Tal y como ha sido apuntado en investigaciones previas (Lamela et al., 2005; Oso et al., 2008), la inmigración gallega se compone de personas procedentes de países con los que ha existido un vínculo histórico a través de la emigración gallega (Venezuela, Argentina o Uruguay en el caso de América Latina; Suiza, Francia, Alemania o Reino Unido, entre los países europeos); pero también de la inmigración "autónoma», es decir, sin lazos con la emigración gallega previa, entre la que encontramos comunidades como la portuguesa, la brasileña, la colombiana o la rumana, entre otras.

Si establecemos una clasificación en referencia a los principales países de nacimiento, destaca, en primer lugar, la comunidad portuguesa, con un 10,2\% sobre el total de personas nacidas en el extranjero. A continuación nos encontramos con un país que comparte la característica de haber sido un importante destino de la emigración gallega, pero del que también procede inmigración «autónoma»: Venezuela, del que también son originarios uno de cada diez inmigrantes. Le siguen Suiza y Argentina, con un 8\% y un 7\% de representación, que también son significativos para la emigración transatlántica y europea. Dos comunidades sin vínculos ocupan los puestos cinco y seis de la tabla; se trata de Brasil (un 6,6\%) y Colombia (un 5,8\%). Tras estos, se intercalan tres países relacionados con la emigración gallega histórica, con proporciones que oscilan entre un 4,6\% y un 4,3\% (Francia, Uruguay y Alemania). Le sigue,

7. Conviene indicar que la medición de la emigración a través de la Estadística de Variaciones Residenciales ofrece serias limitaciones. Así, existe una subestimación importante de los flujos de emigración al extranjero dada la reducida disposición de muchos de los que emigran a darse de baja en el Padrón Municipal de Habitantes; subestimación que es más importante entre los emigrantes de nacionalidad española, al estar al margen del principal proceso de depuración de la fuente que constituyen las bajas por caducidad (respecto a las debilidades de esta fuente para estimar los flujos migratorios, consultar Domingo y Sabater, 2013, y Domingo et al., 2014). 
Gráfico 2. Distribución relativa de la población nacida en el extranjero de acuerdo con los principales países de nacimiento en 2015 en Galicia

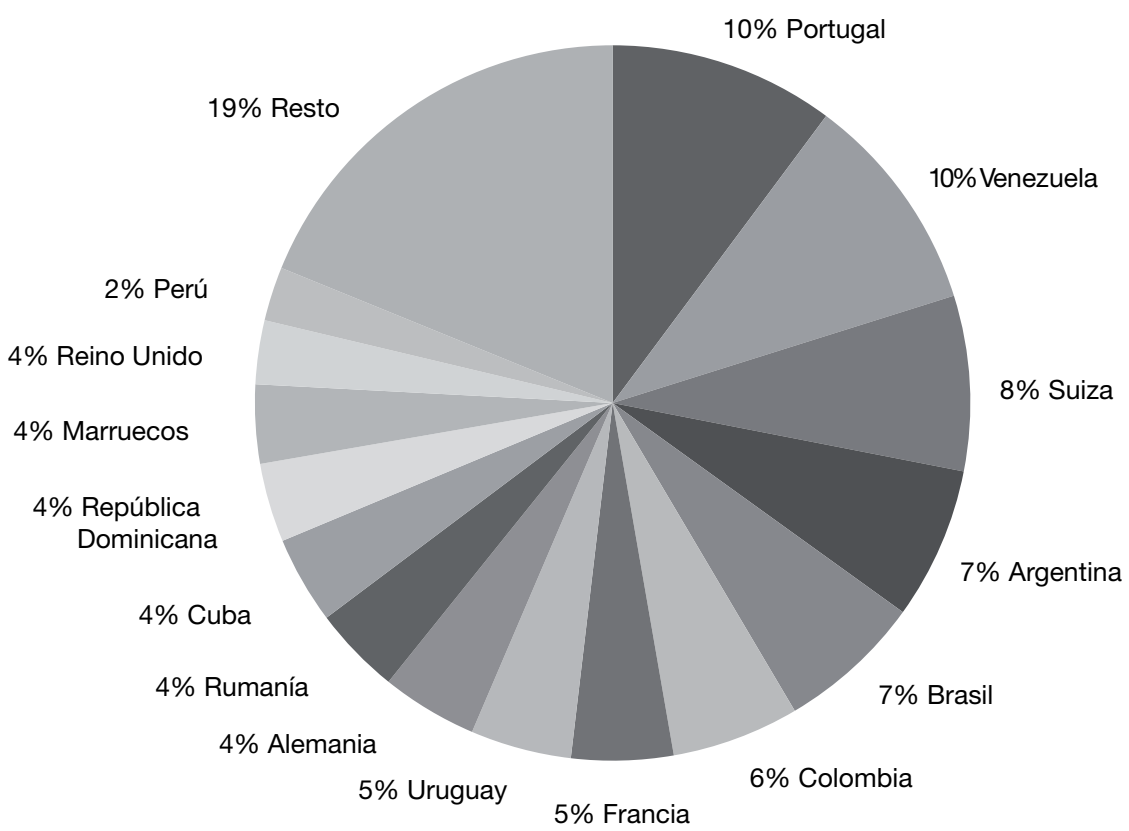

Fuente: elaboración propia en base a la Estadística del Padrón Continuo a 1 de enero de 2015. Instituto Nacional de Estadística.

en la décima posición, Rumanía, con un 4\%, y los países que cierran los últimos cinco puestos de esta clasificación se reparten entre aquellos que guardan lazos con la emigración gallega previa (Cuba, con un 4\%, y Reino Unido, con un 3\%) y los de la inmigración «autónoma» con cierto bagaje migratorio hacia España, como son República Dominicana, Marruecos y Perú (un 3,6\% en los dos primeros casos y un $2,4 \%$ en el tercero).

Comparando el saldo de inmigrantes entre 2007, año álgido en la llegada de inmigración y previo a la entrada en recesión, y la actualidad (2015), no observaremos grandes cambios en las comunidades que participan de los primeros puestos de la clasificación, aunque sí en su distribución y en la magnitud de su contribución al total de población nacida en el extranjero. Las comunidades vinculadas con la emigración gallega retroceden en números absolutos y también en importancia relativa sobre el conjunto de la inmigración, frente al avance de la inmigración que venimos denominando "autónoma». Así, las personas nacidas en Argentina, Uruguay y Suiza reducen su tamaño; las de Reino Unido, Francia y Alemania apenas suman habitantes, y se produce un aumento significativo de comunidades sin ningún tipo de lazo con los movimientos transatlánticos y europeos de la emigración gallega. Rumanía, República Dominicana, Colombia y Marruecos son los países de nacimiento 
que suman más nuevos residentes a la comunidad gallega entre los años que median entre 2007 y 2015.

En lo que respecta a la distribución por el territorio de la población inmigrante, esta es muy desigual. Si empleamos como variable la nacionalidad (esto es, población extranjera) en lugar del país de nacimiento, para evitar la conjunción con el fenómeno del retorno, que es especialmente importante en algunos municipios pequeños, nos encontramos con que, de las poco más de 90.000 personas de nacionalidad extranjera residentes en Galicia a principios de 2015, prácticamente la mitad se asienta en alguna de las siete ciudades (Vigo, A Coruña, Ourense, Lugo, Santiago de Compostela, Pontevedra y Ferrol, por este orden de importancia en cuanto a presencia relativa de población extranjera). A continuación, les sigue un conjunto de municipios que se caracterizan, o bien por su dinamismo económico en tanto que cabeceras comarcales o municipios del área metropolitana de alguna de las siete ciudades principales (como los casos de Vilagarcía de Arousa, Oleiros, Monforte de Lemos, Lalín o Culleredo, entre otros), o bien por ser áreas de importante actividad pesquera (Ribeira, Burela, Marín), sector en el que se ha registrado un proceso de sustitución de la mano de obra nativa por la inmigrante, dato que ha sido bien documentado en el caso de la comunidad caboverdiana en Burela (Oca, 2015).

En el resto de localidades gallegas la presencia extranjera es de mucha menor magnitud e impronta relativa, por lo que cabe esperar que la presencia asociativa se corresponda con un reparto en el territorio que privilegia a las ciudades y a las localidades con mayor dinamismo económico.

\section{Del boom a la fragmentación. El panorama asociativo inmigrante en Galicia entre 2006 y 2016}

A continuación detallaremos la comparativa entre el censo de 2006 y el de 2016, con el objeto de identificar los principales patrones y tendencias de cambio en el asociacionismo migrante.

Con respecto al volumen de asociaciones de inmigrantes, es de destacar el incremento de su existencia a lo largo de esta década. En concreto, en 2016 se contabilizan un total de 79 asociaciones de inmigrantes, mientras que el censo de 2006 registra un total de 55. No obstante, solamente 18 asociaciones han conseguido mantenerse hasta el año 2016, lo que muestra una alta volatilidad de este tejido asociativo. Se confirma, por tanto, un aumento importante del volumen de asociaciones ( 24 más), lo que se explica por el mantenimiento de una minoría de asociaciones, pero sobre todo por la nueva creación de un número importante de ellas. Dicha circunstancia podría tener relación, por una parte, con el aumento sostenido de la inmigración en Galicia hasta el 2011, año que, como se comentó más arriba, marca un punto de inflexión en la recepción de la inmigración en Galicia, con lo que se inicia el estancamiento de la llegada de inmigrantes. No obstante, la población nacida en el extranjero y residente en Galicia aumenta un 26\% en la década de observación (un 19\% si el criterio es el de población extranjera), mientras que el volumen de asociaciones registra 
Tabla 1. Niveles de asociacionismo de la población migrante en Galicia (2006-2016)

\begin{tabular}{lrr}
\hline & 2006 & $\mathbf{2 0 1 6}$ \\
\hline Número de asociaciones & 55 & 79 \\
Población extranjera (Padrón a 1 de enero) & 73.756 & 87.616 \\
Población nacida en el extranjero (Padrón a 1 de enero) & 168.397 & 211.761 \\
Densidad asociativa de la población migrante (por 10.000 personas extranjeras) & 7,5 & 9,0 \\
$\begin{array}{l}\text { Densidad asociativa de la población migrante (por 10.000 personas nacidas en } \\
\quad \text { el extranjero) }\end{array}$ & 3,3 & 3,7 \\
\hline
\end{tabular}

Fuente: elaboración propia en base al Padrón Municipal de Habitantes a 1 de enero de 2006 y de 2016 (Instituto Nacional de Estadística) y de los censos levantados en las investigaciones.

Nota: la información del Padrón de 2016 tiene carácter provisional.

un incremento del $46 \%$. Es decir, aunque existe una correspondencia entre el aumento poblacional y el dinamismo asociativo, es mayor la intensidad de aumento del segundo frente al primero. Si medimos este cambio a través de un indicador de densidad asociativa, como el que han empleado González-Ferrer y Morales (2006), nos encontramos con que, efectivamente, esto se traduce en un aumento de la densidad asociativa migrante en Galicia, ya sea medida a través de la población extranjera, ya sea a través de la población nacida en el extranjero. Otra cuestión interesante es que, comparando nuestros resultados con los obtenidos por estas dos investigadoras para el municipio de Madrid en el año 2006 (3,4 de densidad asociativa medida con población extranjera y 3 con la nacida en el extranjero), comprobamos que la densidad asociativa de inmigrantes en Galicia es mayor, prácticamente el doble en el caso de la población extranjera, y casi idéntica entre las personas nacidas en el extranjero; algo que podría explicarse por los elevados niveles de retorno migratorio que tiene una comunidad como la gallega, con un importante pasado emigrante, y que se plasma en la creación de asociaciones específicas de emigrantes retornados.

En cuanto a su distribución territorial, las asociaciones de inmigrantes aparecen, antes y ahora, localizadas en las dos provincias que registran una mayor atracción de población inmigrante: A Coruña y Pontevedra. Así, en 2006, estas provincias acaparaban el 86\% del total de asociaciones. En el año 2016, se reduce la importancia de estas dos provincias hasta el 69\%, ya que, mientras su número aumenta en A Coruña (pasan de 24 a 35), disminuyen ligeramente en Pontevedra (de 23 a 21) y aumentan notablemente en la provincia de Lugo (de 2 a 16). Aunque no nos detendremos en detalle en este punto, el reparto por municipios de las entidades refuerza el mapa de la distribución de la población inmigrante que hemos comentado: las asociaciones se concentran principalmente en las siete ciudades, en sus áreas metropolitanas en segundo lugar, y, por último, en municipios fronterizos con Portugal o de especial relevancia económica por actividades de pesca y construcción, que se suelen corresponder con cabeceras de comarca.

La comparativa de ambos censos a lo largo de esta última década también nos permite analizar qué tipo de asociaciones por continentes de procedencia se han incrementado en estos años, lo que nos permitirá saber si este incremento 
Tabla 2. Distribución de las asociaciones por continente de adscripción y densidad asociativa en relación con la población extranjera (2006-2016)

\begin{tabular}{llcc}
\hline Continente & & 2006 & 2016 \\
\hline Mezcla de procedencias de diferentes continentes & 8 & 7 \\
\hline América & Número & 24 & 37 \\
& Población & 39.562 & 32.631 \\
& Densidad & 6,1 & 11,3 \\
\hline África & Número & 15 & 25 \\
& Población & 6.639 & 12.599 \\
& Densidad & 22,6 & 19,8 \\
\hline Europa del Este & Número & 1 & 3 \\
& Población & 3.299 & 10.873 \\
& Densidad & 3,0 & 2,8 \\
\hline Asia & Número & 0 & 1 \\
& Población & 1.794 & 4.794 \\
& Densidad & 0 & 2,1 \\
\hline
\end{tabular}

Fuente: censos levantados en las investigaciones.

Nota: se han excluido las asociaciones de personas retornadas, así como las religiosas de carácter migrante de esta tabla. Para la población de Europa del Este, se ha seleccionado la de los países de Europa Central y Oriental que son parte actualmente de la UE. La información del Padrón de 2016 tiene carácter provisional.

responde al aumento de la población migrante de estos flujos en Galicia o si, por el contrario, el aumento de determinadas asociaciones indica una fragmentación del tejido asociativo que revelaría más bien otras razones de orden más organizacional y de competición entre asociaciones.

En primer lugar, detectamos un incremento importante en el número de asociaciones de inmigrantes procedentes tanto del continente americano como del continente africano, lo que parece responder a varias causas en función de las nacionalidades que analicemos. Hay que destacar que, tanto en 2006 como en 2016, la densidad asociativa de la emigración africana es la más elevada, lo que nos sugiere la importante cultura participativa de determinados colectivos inmigrantes, como los marroquíes (que cuentan con siete asociaciones en Galicia) y los senegaleses (con nueve asociaciones). Estos resultados coinciden con lo recogido en otros estudios que destacan el importante dinamismo asociativo del colectivo africano en general (González-Ferrer y Morales, 2006) y del senegalés en particular, con entidades registradas por todos los puntos de residencia que abarcan casi todo el territorio peninsular y las islas (Crespo, 2006; Lacomba, 2001).

En segundo lugar, destaca la densidad asociativa de la emigración americana, una densidad que ha crecido de modo importante con respecto al año 2006. Ello se debe, por una parte, al incremento en la última década de determinada población inmigrante, como por ejemplo la procedente de Perú o Venezuela; aunque, por otra parte, también se detecta una división y una fragmentación del tejido asociativo a lo largo de esta década, en particular un 
importante dinamismo asociativo entre la inmigración peruana, tal y como profundizaremos en el siguiente apartado.

En tercer lugar, también se ha incrementado el volumen de asociaciones de países de Europa del Este, circunstancia que puede vincularse a un incremento muy relevante de la inmigración procedente de esta región (en particular, de Rumanía) con respecto al año 2006; aunque su densidad asociativa es muy inferior si la comparamos con la densidad asociativa del colectivo africano y americano.

Por otra parte, es de destacar que, en cambio, las asociaciones que aúnan una mezcla de procedencias de diferentes continentes hayan descendido, como también ha disminuido el número de asociaciones de personas retornadas. Esto último concuerda con los datos demográficos expuestos arriba y que muestran un retroceso en los últimos años de la inmigración con vínculos históricos con la pasada emigración gallega, frente al avance de la emigración «autónoma».

\section{La transformación del tejido asociativo inmigrante. Alta volatilidad y atención a la exclusión social}

A lo largo de este apartado vamos a dar cuenta del análisis del trabajo de campo realizado, lo que nos proporcionará algunas claves para interpretar de un modo más completo aquellas transformaciones en el tejido asociativo inmigrante que han sido relatadas a partir de la comparativa de los censos 2006-2016. Este análisis cualitativo parte de la realización de 43 entrevistas en profundidad que aglutinan tanto a miembros de asociaciones como a personas expertas y agentes clave. En concreto, se entrevistaron a 25 miembros de entidades (pertenecientes a un total de 21 asociaciones, ya que en algunos casos se entrevistaron a varias personas con distintos cargos de una misma asociación) y se realizó un total de 18 entrevistas a diferentes agentes clave, como mediadoras interculturales, técnicas de ayuntamientos o miembros de varias ONG y de sindicatos. Las entrevistas fueron llevadas a cabo en las cuatro provincias gallegas, incluyendo tanto las principales ciudades como villas y zonas más rurales.

Los resultados del trabajo de campo apuntan fundamentalmente transformaciones en dos ámbitos: en el volumen y en la composición de las asociaciones, y en la orientación de las mismas, es decir, el tipo de objetivos y actividades que llevan a cabo; lo que coincide con los resultados recogidos a partir de la comparativa realizada entre los dos censos.

En primer lugar, se constata una elevada volatilidad en estas asociaciones, que se manifiesta tanto en el cierre de muchas de ellas como en la bajada importante en el número de personas o la base social que componen aquellas que se han mantenido a lo largo del tiempo. Sin embargo, simultáneamente, se constata el surgimiento de nuevas asociaciones con otros colectivos migrantes como protagonistas. En segundo lugar, se detecta una transformación en otro sentido: un giro en la orientación de las entidades, puesto que muchas de ellas se especializan en la atención a las personas inmigrantes en riesgo de exclusión social. Como veremos, muchas asociaciones han tenido que dejar de lado acti- 
vidades orientadas a la integración cultural de las personas inmigrantes para centrarse únicamente en la atención a la exclusión social. Asimismo, como ya se ha señalado, también hemos recogido la creación de nuevas asociaciones que han surgido con objetivos muy específicos, como es el caso de las asociaciones de mujeres o de corte religioso.

\subsection{La elevada volatilidad asociativa}

A lo largo de estos años hemos asistido al cierre de asociaciones, al mismo tiempo que otras, a pesar de su mantenimiento a nivel formal, han quedado en un estado "latente», es decir, sin apenas realizar actividades y quedando su funcionamiento en manos de una o dos personas. En concreto, como se comentó arriba, desde 2006 han desaparecido 35 asociaciones de inmigrantes y solamente se han mantenido 18 de ellas a lo largo de esta década.

Muchos han sido los factores que han influenciado esta volatilidad, aunque vamos a mencionar los dos más importantes. Por una parte, el ámbito de la atención a las personas inmigrantes ha dejado de estar presente en la agenda política (tanto a nivel municipal como autonómico y estatal), y ello ha tenido unos efectos claros en el recorte de ayudas económicas a este tipo de entidades. Por otra parte, como comentamos, ha habido un cambio en el ciclo migratorio, que se plasma en la reducción de la inmigración y en el aumento de la reemigración y el retorno.

En el trabajo de campo realizado es constante la alusión al impacto que ha tenido el hecho de que la atención a los inmigrantes haya "caído» de la agenda política, tanto a nivel local como autonómico y estatal. Como recoge Fernández (2017), la Xunta de Galicia posee dos programas para inmigrantes: subvenciones a los ayuntamientos para políticas de integración y ayudas a entidades del tercer sector (y durante años a asociaciones de inmigrantes). Los presupuestos para ambos programas se redujeron significativamente desde el año 2009 (con la primera legislatura de Núñez Feijoo) hasta el año 2015, puesto que pasaron de ser casi 6,8 millones de euros anuales en 2009 a quedar reducidos a 0,5 millones en 2015, tal y como se puede consultar en detalle en el gráfico 3.

Las personas entrevistadas han relatado diferentes ámbitos en los que se ha plasmado esta pérdida en la atención a las personas inmigrantes. Por un lado, señalan el cese de ayudas económicas para actividades asociativas y, por otro, el recorte en las subvenciones a los locales de las asociaciones. Así, muchas de las asociaciones han tenido que perder un punto de referencia clave como es el local asociativo, un lugar desde donde se daban a conocer y que consideran crucial para el desarrollo de sus objetivos. Dejar el local ha supuesto adaptar las actividades a este hecho. Como consecuencia, muchas asociaciones se han quedado en un estado latente, manteniendo un número de teléfono para atender aquellos casos más urgentes, pero dejando de lado otro tipo de actividades sociales y culturales. La siguiente entrevistada hace alusión a la pérdida del local de Amigos en España. Asociación Latino Eslava (AMESPA), una asociación radicada en A Coruña con la que colaboraba. Señala el impacto que ha tenido 
Gráfico 3. Presupuesto autonómico destinado a subvencionar programas de atención a inmigrantes en ayuntamientos y entidades sin ánimo de lucro (Fernández, 2017: 73).

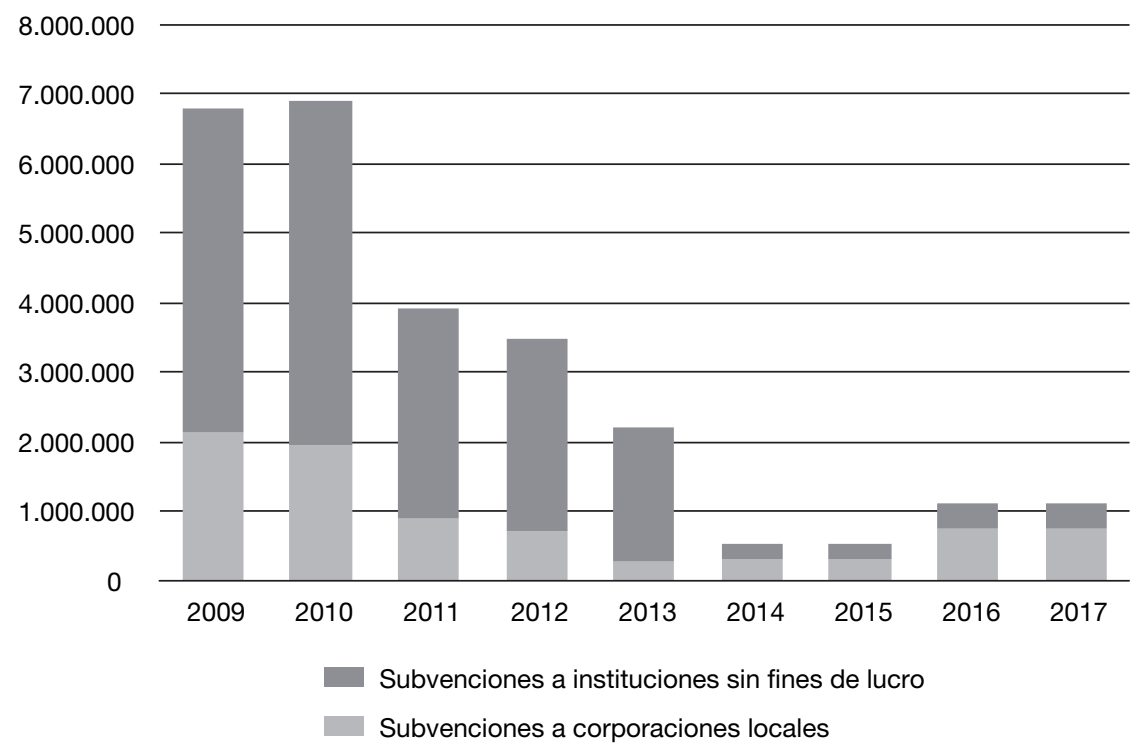

Fuente: Fernández (2017: 73), elaborado con datos de los presupuestos de la Xunta de Galicia (20092017), Consellería de Facenda.

la derogación de una norma en Galicia que subvencionaba los locales de las asociaciones de inmigrantes ${ }^{8}$.

P: [...] Sí que los últimos meses, quienes manteníamos la asociación éramos los propios implicados en la asociación, y lo manteníamos, ayudábamos a colaborar, a comprar rifas, o sea, a veces, era una colaboración directa de, bueno, pago mi cuota de socio de todos los siguientes 20 años (risas), o a veces era una..., colaboración indirecta, bueno, vale, compro rifas o..., pero llegó un momento que ya no se pudo mantener, y se mantuvo durante mucho tiempo por el hecho de que..., hacían reparto de alimentos, entonces, claro, una forma de dejar a mucha gente sin..., y de hecho, todo lo que, material que había se donó, se tuvo que dejar el local, ya el año pasado, el año pasado, entonces, claro, sin local es más difícil mantener las actividades y..., o sea, implicar a la gente. La gente se implicaba en parte porque iba todos los meses a buscar alimentos, en parte porque había un ropero que funcionaba muy bien, y la gente iba a buscar ropa,

E: Hay muchísimas asociaciones, bueno, por lo menos en Vigo, con las que yo colaboraba que tenía contacto que, fuera local, fuera actividades.

8. Dicha ayuda se concretaba en la convocatoria anual de las «Subvenciones a entidades sin ánimo de lucro para desarrollar proyectos destinados a favorecer los procesos de acogida e integración de la población inmigrante y retornada en la Comunidad Autónoma Gallega» y no se convoca desde el año 2011. 
P: Es que una cosa implica a la otra, si tú no tienes un local, no tienes forma de contactar con la gente, no hace falta a veces ser un local muy grande, pero el hecho de tener un local es como un punto de referencia, que la gente puede ir... Sabes que estás ahí, sabe que la gente está ahí..., pero sin local [...] porque pagar un alquiler, a ver, la gente tiene problemas para pagar su propio alquiler, más aún pagar un alquiler..., más aún para pagar una cuota de socios, entonces sí que ahí hubo, bueno, de hecho, derogaron una que era para asociaciones.

(P: portavoz del Foro Galego de Inmigración, de Santiago de Compostela, y miembro de la asociación AMESPA, de A Coruña)

En segundo lugar, además del cese de ayudas económicas, también hemos detectado cómo la incipiente participación política conseguida por el tejido asociativo inmigrante a nivel municipal ha decaído de un modo claro. Por ejemplo, en algunas ciudades, como Vigo, existía el Consello Municipal das Migracións (Consejo Municipal de las Migraciones), un órgano consultivo que se reunía a nivel local y que estaba formado, entre otras, por asociaciones de inmigrantes que podían proponer mejoras en el ámbito de la integración, sin embargo no se reúne desde el año 2009. Lo mismo ocurre con los planes de inmigración y convivencia, en suspenso en Vigo desde el año 2013. Esta pérdida de protagonismo de las migraciones a nivel político ha ejercido un impacto negativo en las asociaciones. Muchas nos relatan cómo han sentido que la integración social de las personas inmigrantes no constituía, en realidad, una preocupación política real, ya que una vez que la crisis económica eclipsa la agenda política, las personas inmigrantes son tratadas como mera mano de obra, olvidando totalmente las demandas de participación social y política plena de las asociaciones de inmigrantes en la sociedad de acogida. A mayores, esta pérdida se traduce también en la paralización de proyectos ${ }^{9}$ y de actividades interculturales en colaboración con los diferentes ayuntamientos y en la negativa por parte de las instituciones de ceder espacios públicos para actividades culturales y/o reivindicativas de las asociaciones. En este sentido, diferentes agentes clave en contacto con la inmigración, como la mediadora en la Oficina Municipal de Inmigración de Vigo, son totalmente conscientes de que "hubo mejores momentos» con respecto a las políticas de integración social a nivel gallego y municipal, y que ello ha derivado en un debilitamiento de cierto tejido asociativo. Coincide con este diagnóstico la técnica de inmigración de UGT de Ourense, cuando señala el cese de las jornadas interculturales que se realizaban una vez al año en esta ciudad, en la que participaban diferentes colectivos de inmigrantes, tal y como se recoge a continuación.

T: Durante... tres o cuatro años, los servicios sociales aquí en Ourense hicieron, pues, era en septiembre, unas jornadas de interculturalidad, en la cual lo

9. Por ejemplo: en 2011 se paralizó el proyecto titulado En galego tamén noutros mundos, promovido en el año 2008 por la Concejalía de Bienestar Social del Ayuntamiento de Vigo, un proyecto realizado en colaboración con el tejido asociativo inmigrante y que pretendía dar visibilidad a las lenguas y a las culturas de origen de los colectivos migrantes, así como facilitar la enseñanza de la lengua y de la cultura gallegas. 
hacían, eran unos estands, ponían dominicanos, colombianos, venezolanos, senegaleses, etc., y entonces cada uno tenía un estand distinto, hacían comidas, eh..., tema cultural, y luego hacían una, como una jornada de folclore, pues donde hacían bailes, músicas tradicionales y..., luego después había un tema pues de charlas, ¿vale? De charlas, de coloquios, pero ya el año pasado no lo hicieron, y hace dos, creo recordar que tampoco, creo que ya lo...

E: Pero porque hubo recortes.

M: Me imagino que sería un tema de recortes...

(T: técnica de inmigración de UGT, de Ourense)

Hay que señalar, no obstante, que, antes de esta salida de la agenda política, algunas asociaciones ya tenían un discurso crítico sobre algunas actividades promovidas por los ayuntamientos cuando se limitaban únicamente a reproducir ciertos estereotipos relacionados con los países de origen (como la gastronomía), y trasladaban a las instituciones la demanda de una mayor profundización en la riqueza y en la diversidad cultural de los distintos colectivos migrantes. Antes de que se produjera un paso adelante en este sentido y se prestara atención a estas incipientes demandas de las asociaciones más críticas, todo el proceso quedó paralizado. Es decir, antes de evolucionar hacia la segunda fase recogida por Zapata-Barrero (2004) en la que se debería producir una demanda de derechos plenos, todo quedó en suspenso. Ello provocó una gran sensación de frustración en el tejido asociativo inmigrante que terminó por desgastar y debilitar su nivel de participación, sintiendo por momentos que su participación a nivel institucional no había dado los frutos esperados. En el siguiente fragmento de entrevista, la vicepresidenta de ABRIGA (Asociación de Brasileiros de Galicia) se muestra especialmente crítica con los estereotipos sobre Brasil manejados por algunas instituciones municipales a la hora de realizar actividades interculturales.

E: Ya, eh... ¿Cambiarías algo entonces en este sentido para poder mantener vuestra lengua, vuestra cultura?

VP: Sí.

E: ¿Qué facilitaría que realmente se pudiera hacer?

VP: A mí me gustaría que la cultura brasileña fuera introducida aquí, que se mostrara como cultura brasileña, no como lo que los españoles están acostumbrados a ver que es Brasil, que piensa que solo es eso, por ejemplo: la literatura brasileña. Yo creo que no es conocida y debería ser más conocida, intentamos varios eventos sobre eso, eh... No hay tampoco, se intentó hacer una biblioteca itinerante traducido al gallego de escritores extranjeros... Me parece superimportante dar a conocer escritores, pintores, una película, otras cosas que no sean la samba, la caipiriña y la capoeira, y... el carnaval, ¡Basta! ¡No! ¡Mucho más! ¡Mucho! A mí me asustó cuando, por ejemplo, vi a gente aquí que no sabía que Óscar Niemeyer era brasileño.

(VP: vicepresidenta de la Asociación ABRIGA, de Vigo) ${ }^{10}$

10. Esta entrevista fue desarrollada en gallego y portugués, y traducida posteriormente al español. 
Sin embargo, la pérdida de importancia de la inmigración en la agenda política no ha sido el único factor en la transformación del tejido asociativo. Como se comentó arriba, el cambio de ciclo migratorio ha impactado también en la composición y en el nivel de participación en las asociaciones. La reemigración hacia otros países y el retorno al lugar de origen ha mermado la composición y el funcionamiento de las asociaciones. En este sentido, en el trabajo de campo se ha detectado un estado «latente» en muchas asociaciones de inmigrantes, fundamentalmente en aquellas compuestas por personas procedentes de América Latina, un colectivo que lideraba en el año 2006 el incipiente tejido asociativo inmigrante en Galicia. A continuación, la presidenta de la asociación Madres Latinas, una entidad pionera en Vigo y creada en el año 2002, explica la pérdida de pulso de las asociaciones de inmigrantes latinoamericanos en esta ciudad.

P: Desgraciadamente, eh..., eh..., teníamos, había una asociación de, de paraguayos, están en stand by, una asociación de colombianos, están en stand by, otra asociación de, de, bueno, de uruguayos, los dos, no están stand by, ipero ya no hay local!

(Presidenta de la asociación Madres Latinas, de Vigo).

En el trabajo de campo hemos detectado que la base social de las asociaciones ha descendido de modo relevante en estos años. El presidente de la Asociación Sociocultural Afrolatina (ASALA) de Ourense alertó en su entrevista del cambio experimentado en su organización. En la actualidad, las personas que se acercan a ella llegan con unos problemas económicos importantes, y ya no es frecuente, como era hace años, la propuesta de actividades o el trabajo voluntario. La crisis económica, el paro y la precariedad laboral afectaron negativamente tanto la base social de estas asociaciones como su capacidad de realizar actividades.

P: iniciativa, por ejemplo, pues de vez en cuando te viene unos y te dicen: «Oye, ipor qué no hacemos esto, por qué no tal?». Eso era eh... Eran, digamos, iniciativas muy positivas. Hoy día no. Hoy día la gente ya no viene con eso, no. Viene con problemas, solo con problemas, incluso si vas a organizar una actividad es difícil conseguir voluntarios, porque la gente, aunque no está trabajando, aunque no está haciendo nada, parece que no, que está pensando en otras cosas y está ocupada con... otro. Solamente buscando trabajo, buscando medio de vida o buscando pero por lo que es esto de... la asociación o las actividades así sociales iniciativas, voluntariado, no, no.

(P: presidente de la Asociación Sociocultural Afrolatina, ASALA, de Ourense).

También en Ourense, la ONG Teranga ha detectado otra variable de interés que ha influido de modo negativo en el funcionamiento de las asociaciones: la reemigración de ciertos líderes asociativos a otros países o la sustitución de unos líderes por otros, que deja a algunas asociaciones huérfanas de sus directivos y directivas más activas. 
E: ¿Vosotras intentáis trabajar con todo tipo de asociaciones? ¿de diferentes nacionalidades, no?

T: Sí, sí, que intentamos, es verdad que aquí en Ourense hay poco, poco por decir nada, hay la de senegaleses, pero bueno, funciona...

E: Sí, que antes igual sí que... A eso es a lo que me refiero.

T: Creo que el tema de la subvención ahí afectó, ya no tienen.

E: Claro.

T: Para pagar ese local, como no tienen... Quien está, quien lidera también afecta, pues ahora hay una gente, hay otra, bueno, todo eso afecta, la de venezolanos también, aquí pues había una señora que movía mucho. Después se marchó, bueno, pero ahora ya no sé lo que están haciendo...

(T: técnica de inmigración en la Fundación Juan Soñador- Programa Teranga, de Ourense) ${ }^{11}$

Por otra parte, al mismo tiempo que muchas asociaciones cerraban sus puertas a lo largo de esta década o se quedaban en un estado de latencia, otras nuevas las abrían, protagonizando un fenómeno de «fragmentación». Así, si analizamos la composición de las asociaciones atendiendo estrictamente al país de origen de sus miembros, se constata un proceso de fragmentación relevante de asociaciones de los colectivos de peruanos, senegaleses y, en menor medida, caboverdianos. Nos referimos a fragmentación en el sentido de que, en una misma localidad, detectamos varias asociaciones de un mismo país de procedencia, que han surgido por dos motivos principales. Por una parte, algunas de ellas han nacido a partir de la fisión de una asociación anterior que aglutinaba a todo el colectivo; por ejemplo, esto pasó con el tejido asociativo caboverdiano en Burela o con los migrantes peruanos en Vigo (en ambos casos, hemos detectado tres asociaciones del mismo colectivo en la misma localidad) ${ }^{12}$.

No obstante, por otra parte, las asociaciones recién creadas poseen una nueva orientación que justifica el surgimiento de las mismas. Esto acontece cuando las mujeres de un colectivo deciden crear su propia asociación para realizar actividades destinadas específicamente a su integración social. Esta ha sido la motivación para la creación, por ejemplo, de la asociación de mujeres senegalesas Domu África de A Coruña o la asociación Al Amal de mujeres marroquíes de Marín (Pontevedra). Ellas han decidido poner en marcha este tipo de entidades, dado que las asociaciones de senegaleses y marroquíes existentes no recogían entre sus objetivos la atención específica a las mujeres inmigrantes de estos colectivos. En este sentido, el incremento de mujeres en los flujos africanos ha influido en el surgimiento de este tipo de asociaciones. La presidenta de Domu África (de mujeres senegalesas) expone a continuación por qué decidieron crear esta asociación:

11. Esta entrevista fue desarrollada en gallego, y posteriormente traducida al español.

12. Hay que señalar que este dinamismo asociativo de la inmigración peruana no es un fenómeno exclusivo de Galicia, ya que se ha detectado también en otros ámbitos territoriales, como en el tejido asociativo inmigrante de Madrid (González-Ferrer y Morales, 2006). 
A: Por..., por la igualdad de las mujeres [...]. Sí, antes hubo asociación y siempre fueron los hombres, y no nos dejaban [...] participar, y nosotras decidimos..., decidimos, eh..., crear la asociación para..., para hacer igual que los hombres, porque aquí es... ya no estamos en Senegal.

Por otra parte, también dentro del tejido asociativo senegalés se detecta un surgimiento de nuevas asociaciones de corte religioso cuya finalidad principal es juntarse para el rezo. En este sentido, en Galicia hay tres hermandades o cofradías religiosas musulmanas creadas por el colectivo senegalés que funcionan como motores de los lazos de solidaridad y sociabilidad de sus miembros, un aspecto analizado también en otros estudios sobre dicha comunidad asentada en España (Lacomba, 2001).

\subsection{La especialización en la atención a la exclusión social}

La transformación del tejido asociativo también se ha plasmado en el tipo de orientación que han asumido muchas asociaciones de inmigrantes. Así, la especialización en la atención a personas inmigrantes en riesgo de exclusión social ha sido clara. Nuevamente, son varios los factores que han provocado este cambio:

1. La crisis económica y su impacto específico en la población inmigrante, que ha obligado a reorientar las actividades de las asociaciones.

2. El ya mencionado giro de la "agenda política», que ha dejado de lado temas como la integración social y cultural de las personas inmigrantes y que ha provocado que únicamente queden en pie ciertas líneas de trabajo relacionadas con la atención a población en riesgo de exclusión social.

En el siguiente fragmento, la portavoz del Foro Galego de Inmigración relata su visión sobre la evolución en la orientación de las asociaciones de inmigrantes: cómo muchas tuvieron que dejar de realizar actividades culturales, como ciclos de conferencias o de cine, y centrarse en las necesidades más urgentes que planteaba el colectivo de migrantes, como el reparto de alimentos o de ropa.

E: Vale, vale, vale, eh... ¿Cómo dirías que se comportan las instituciones en cuanto a la inmigración? ¿ ¿Os sentís apoyadas?

P: Realmente, no. De hecho... Bueno, he vivido todo lo que fueron los cambios de, de normativa, de los últimos años y evidentemente cada vez va a peor. El apoyo que tenían las asociaciones o el fomento de asociaciones de inmigrantes ya no existe. De hecho, esa orden de ayudas ya no existe. Antes sí que había esto..., ayudas para..., sí, sobre todo para actividades culturales, local...

E: Recuerdo.

P: Fomento de la cultura, claro de fomento de...

E: Era muy importante. 
P: De hecho, la [asociación] Clam tenía eso, actividades para el fomento de la cultura latinoamericana, y se hacía un ciclo de conferencias, ciclos de cine y tal, pero... A día de hoy, esa orden no existe y..., casi todas las asociaciones de inmigrantes que quedan en pie se dedican al reparto de alimentos y al ropero. O sea, eh...

E: Cosas casi de exclusión social, ¿no?

P: Sí.

E: Actividades casi de exclusión social.

P: Totalmente, totalmente. De hecho, por ejemplo, no sé si conocéis a..., bueno, contacto Boiro.

E: No.

P: No, contacto Boiro es una ONG que trabaja en toda la zona de Ribeira, que..., de hecho, la, bueno, quienes la estaban llevando eran un grupo de..., de chilenos.

E: Ajá.

P: Y..., a día de hoy, las actividades están reducidas a tener reparto de alimentos y un ropero, igual que los últimos momentos de AMESPA, cuando antes de disolverse, igual que la rumana, que también hacía reparto de alimentos, vemos que las necesidades fueron cambiando. Ahora no te puedes permitir hacer un ciclo de cine latinoamericano, porque es que la gente no tiene tiempo de ir a...

(P: portavoz del Foro Galego de Inmigración, de Santiago de Compostela, y de la asociación AMESPA, de A Coruña).

En esta misma línea, la asociación MIRA, de colombianos en Ourense, se ha especializado también en la realización de lo que denominan Operación Kilo, con el objetivo de recoger alimentos en supermercados y repartirlos entre las familias con las que trabajan. Como la presidenta de la asociación comenta a continuación, es ella misma la que se encarga del ámbito social dentro de su entidad, visitando y atendiendo a un total de cuarenta y dos hogares en riesgo de exclusión social. Dada la situación detectada, esta entidad se ha centrado principalmente en el reparto de alimentos a familias y ha pospuesto por el momento la realización de otro tipo de actividades culturales.

E: Vale y, ¿cuál es tu papel un poco dentro de la entidad? Presidenta, ¿no?

P: Ahorita me toca a mí, por ejemplo, lo social, ahorita lo social... Dedicarme a tocar puertas, por decir algo, supermercados, donde se hace la Operación Kilo.

E: Ajá.

P: Para recoger alimentos.

E: Alimentos.

P: Y esos alimentos repartirlos entre las familias que tengo, por... Yo tengo ahorita a mi cargo cuarenta y dos familias para un total de 115 personas.

(P: presidenta de la asociación MIRA de colombianos, de Ourense)

Este cambio de orientación, unido a la pérdida de socios y socias, ha derivado en una transformación de muchas entidades: una única persona, con su teléfono móvil, atiende a los casos más urgentes. Lleva a cabo acompañamien- 
tos para la realización de trámites burocráticos, petición de ayudas sociales, etc. La asociación de mujeres marroquíes Al Amal, de Marín, es un buen ejemplo de dicho proceso. Esta asociación fue creada en 2008 y durante varios años se dedicó a realizar diferentes tipos de actividades culturales, por ejemplo: la participación en fiestas interculturales en colaboración con los servicios sociales de Marín, donde mostraba diferentes aspectos de la cultura árabe, como la gastronomía o la vestimenta; las salidas o excursiones con sus hijos e hijas por los alrededores, y la oferta de clases de árabe para los niños y niñas del colectivo inmigrante marroquí residente en este municipio. Sin embargo, su vicepresidenta nos comenta que, desde el año 2011, la actividad ha bajado de un modo drástico y la asociación «existe, como no existe». Únicamente quedan las clases de árabe un día a la semana y los acompañamientos que realiza ella misma (a hospitales, comisarías, juzgados, etc.) de modo voluntario a aquellas mujeres marroquíes que necesitan una mediación lingüística y cultural urgente.

En el siguiente fragmento, la vicepresidenta de la asociación nos comenta la evolución y el descenso de actividades que se produjo en su asociación, causada, entre otros factores, por el descenso de subvenciones y el desinterés institucional por parte del Ayuntamiento a la hora de realizar actividades interculturales.

Vc: Ah, antes trabajaba [la asociación], pero ahora ya no hacen nada.

$\mathrm{E}:$ ¿ $\mathrm{No}$ ?

Vc: Antes sí, la verdad. Hacían, hacían, bueno, eh... ¿Cómo se llama? Sacar la cultura de, de... La ropita, muchas cositas, los dulces, lo que te comenté, hasta la asistenta social nos llamaba, pero ahora ya no...

E: ¿Hacíais actos un poco para mostrar, mostrar la comida, la ropa...? ¿Un día, por ejemplo, de distintas culturas?

Vc: Sí, pero ahora ya no... Ya no lo hacen.

E: Se dejó de hacer, vale, entonces, ahora... ¿Por qué se dejó de hacer...? ¿Por dinero?

Vc: Ajá.

E: Ya no hay dinero.

S: No, no, no.

E: No, entonces ahora simplemente os dedicáis a las clases.

Vc: Namás que eso. Marín)

(Vc: vicepresidenta de la asociación de mujeres marroquíes Al Amal, de

\section{Conclusiones}

Las transformaciones demográficas, de ciclo migratorio, de agenda política, la crisis económica y las propias dinámicas internas de las asociaciones han dejado una huella importante en el tejido asociativo inmigrante a lo largo de esta década. Así, la evolución del tejido asociativo en fases que Zapata-Barrero (2004) pronosticaba se ha colapsado en el caso gallego. A pesar de que la llegada de inmigrantes se ha ralentizado en los últimos años y de que la atención que 
se les dedica ya no se circunscribe únicamente a las personas recién llegadas, otras variables han impedido que las asociaciones pasen a una segunda fase que se caracterizaba por la demanda de justicia y plenos derechos. Muchas de las entidades que han permanecido activas a lo largo de esta década han tenido que modificar su orientación y especializarse en la atención a la exclusión social, dejando de lado otros objetivos más reivindicativos que cabrían esperar después de una década de funcionamiento asociativo. Tampoco hemos constatado una consolidación en la profesionalización de estas asociaciones con el paso del tiempo, puesto que todas ellas se han quedado en una tipología de carácter más voluntarista (Garreta y Llevot, 2013), como consecuencia fundamentalmente del corte repentino de ayudas económicas y la salida del ámbito de la inmigración de la agenda política. En este sentido, el continuo cese de programas de integración social (a nivel local y autonómico) ha dejado una huella importante en el desgaste de la participación asociativa. Así, y fundamentalmente a partir de 2010, apenas quedan herramientas de colaboración entre las administraciones y las asociaciones, por lo que muchas de ellas se han quedado con un elevado grado de frustración al sentirse de algún modo instrumentalizadas políticamente en el pasado y ninguneadas en el presente; conscientes de que, en realidad, estas distintas administraciones desde siempre habían asumido a la población inmigrante únicamente como mano de obra, y no en su calidad de ciudadanía.

Al mismo tiempo, hemos confirmado una elevada volatilidad de las asociaciones y una dificultad importante para su mantenimiento y su consolidación a lo largo del tiempo. Lo que sí se ha constatado es cierto dinamismo asociativo que merece una atención particular en el caso de las migraciónes africana (sobre todo senegalesa) y americana (sobre todo peruana), un dinamismo que no es exclusivo del territorio gallego. En estos casos, sí podemos coincidir con Zapata-Barrero (2004) sobre la importancia que posee la defensa de las identidades culturales propias en esta segunda fase de evolución de las asociaciones, sobre todo para determinados colectivos con una cultura migratoria muy relevante.

Sin embargo, este dinamismo parece afectar únicamente a unos pocos grupos. La pauta general que hemos detectado en el trabajo de campo es una especie de cadencia asociativa que provoca que muchas de las asociaciones que han sobrevivido a lo largo de los años se hayan visto reducidas a una o dos personas que, a través del teléfono, gestionan y atienden aquellos casos más urgentes.

El futuro del maltrecho tejido asociativo inmigrante en Galicia es incierto. En un contexto de nulo apoyo institucional y de una crisis económica que ha afectado específicamente a la población inmigrante, la estrategia para el mantenimiento de las asociaciones parece que pasa por tejer redes de colaboración entre ellas mismas (compartir gastos, locales, etc.), buscando también el apoyo de otros actores de la sociedad civil, como determinadas ONG proinmigrantes. Una colaboración que, si bien no está exenta de conflictos, puede ser positiva en el actual contexto hostil a la hora de reivindicar un espacio de participación social que sigue siendo clave para una población a la que le es negada su participación política plena a través del sufragio. 


\section{Referencias bibliográficas}

AbOuSSI, Mourad; RaYa, Enrique y EsPadAs, M. Ángeles (2013). «Asociacionismo inmigrante, tercer sector y Administración Pública en Andalucía: Dimensiones de política, necesidades de gobernanza y oportunidades para la ciudadanía activa». En: RaYA, Enrique; EsPADAS, M. Ángeles y ABOUSSI, Mourad (coords.). Inmigración y ciudadania activa. Barcelona: Icaria.

Aguilar, M. José y Buraschi, Daniel (2013). "Asociacionismo e intervención social con inmigrantes». En: RaYA, Enrique; EsPaDAs, M. Ángeles y ABOussi, Mourad (coords.). Inmigración y ciudadanía activa. Barcelona: Icaria.

AJA, Eliseo; ArANGO, Joaquín y Oliver, Josep (eds.) (2012). Inmigración y crisis: Entre la continuidad y el cambio. Barcelona: CIDOB.

APARICIO, Rosa (2011). «Participación ciudadana y asociaciones de inmigrantes». Oñati socio-legal series, 1(3), 1-23.

APARICIO, Rosa y TORNOS, Andrés (2010). Las asociaciones de inmigrantes en España: Una visión de conjunto. Madrid: Ministerio de Trabajo e Inmigración.

ARANGO, Joaquín (2010). «Después del gran boom: La inmigración en la bisagra del cambio». En: AJA, Eliseo; ARANGO, Joaquín y OLIVER, Josep (eds.). La inmigración en tiempos de crisis: Anuario de la inmigración en España (edición 2009). Barcelona: CIDOB.

CACHÓN, Lorenzo (2014). «La nueva emigración desde España y Cataluña en la Gran Recesión (¿2007-2016?): Unas reflexiones provisionales». En: SÁNCHEZ-MONTIJANO, Elena y ALONSO, Xavier (eds.). Nuevos flujos y gran recesión: La emigración en Cataluña, España y la UE. Barcelona: CIDOB.

Cebolla-BoAdo, Héctor y López-SAla, Ana (2015). «Transnational Latin American Immigrant Associations in Spain During the Economic Recession: A Top-Down Model of Integration and Transnationalism at Stake?». En: AYSA-LASTRA, María y CACHÓn, Lorenzo (eds.). Immigrant Vulnerabilty and Resilience. Nueva York: Springer. <https://doi.org/10.1007/978-3-319-14797-0_9>

CRESPO, Rafael (2006). «Participación y asociacionismo senegalés, de la visibilidad a la conexión transcontinental». En: JABARDO, Mercedes (ed.). Senegaleses en España: Conexiones entre origen y destino. Madrid: Ministerio de Trabajo y Asuntos Sociales.

DANESE, Gaia (2001). "Participation beyond citizenship: Migrants' associations in Italy and Spain». Patterns of Prejudice, 35(1), 69-89. $<$ https://doi.org/10.1080/003132201128811070>

DOMINGO, Andreu y BlANES, Amand (2015). «Inmigración y emigración en España: Estado de la cuestión y perspectivas de futuro». En: ARANGO, Joaquín; MOYA, David; Oliver, Josep y SÁnCHEZ-Montijano, Elena (eds.). Flujos cambiantes, atonía institucional: Anuario de la inmigración en España 2014. Barcelona: CIDOB.

- (2018). "The Galician diaspora in the 21st Century: Demographic renovation as a response to the economic crisis». En: DePALma, Renée y PÉrEZ-Caramés, Antía (eds.). Beyond Global Cities: A Case Study of Emerging Superdiversity. Nueva York: Springer. <https://doi.org/10.1007/978-3-319-66305-0_8>

Domingo, Andreu y SABATER, Albert (2013). «Crisis económica e inmigración: La perspectiva demográfica». En: AJA, Eliseo; ArANGO, Joaquín y Oliver, Josep (eds.). Inmigración y crisis: Entre la continuidad y el cambio. Barcelona: CIDOB.

Domingo, Andreu; SABATER, Albert y OrTEga, Enrique (2014). «¿Migración neohispánica?: El impacto de la crisis en la emigración española». Empiria, 29(1), 39-66. <https://doi.org/10.5944/empiria.29.2014.12940> 
FERNÁNDEZ, Belén (2017). «Políticas de integraciónda poboación estranxeira en Galicia: migracións e política lingüística». En: RODRÍGUEZ, Laura y VÁZQUEZ, Iria (eds.). Muller inmigrante, lingua e sociedade. Vigo: Galaxia.

- (2018). «Migratory trends and their relation to specific policy regarding migrations in Galicia». En: De Palma, Renée y Pérez-Caramés, Antía (eds.). Beyond Global Cities: A Case Study of Emerging Superdiversity. Nueva York: Springer. <https://doi.org/10.1007/978-3-319-66305-0_9>

GarretA, Jordi y LleVot, Núria (2013). «Las asociaciones de inmigrantes africanos: Organización, proyección y actuaciones». Revista Internacional de Sociología, 71(extra 1), 15-38. <https://doi.org/10.3989/ris.2012.09.01>

GONZÁlEZ-FERRER, Amparo y MORALES, Laura (2006). «Las asociaciones de inmigrantes en Madrid: Una nota de investigación sobre su grado de integración política». Revista Española del Tercer Sector, 4, 129-173.

LACOMBA, Joan (2001). «Inmigrantes senegaleses, Islam y cofradías». Revista Internacional de Sociología, 29, 163- 187.

LACOMBA, Joan y GINER, Jordi (2013). «La participación en asociaciones de los inmigrantes africanos: Vías de interpretación del distanciamiento asociativo». Revista Internacional de Sociología, 71(extra 1), 67-89. $<$ https://doi.org/10.3989/ris.2012.09.10>

LAMELA, Carmen; LÓPEZ, Diego y Oso, Laura (2005). «La inmigración internacional en Galicia: Latinoamericanos, comunitarios y otros». En: SolÉ, Carlota; IzQUIERDO, Antonio y AlARCÓN, Amado (eds.). Integraciones diferenciadas: Migraciones en Cataluña, Galicia y Andalucía. Barcelona: Anthropos.

LÓPEZ-SALA, Ana y Oso, Laura (2015). «Inmigración en tiempos de crisis: Dinámicas de movilidad emergentes y nuevos impactos sociales». Migraciones, 37, 9-27. <https://doi.org/10.14422/mig.i37.y2015.001>

MONCUSí, Albert; LACOMBA, Joan y AlBERT, María (2013). «Asociaciones de inmigrantes africanos en la Comunidad Valenciana: Su papel y relaciones con entidades y administraciones». En: RaYA, Enrique; EsPadas, M. Ángeles y ABOussi, Mourad (coords.). Inmigración y ciudadanía activa. Barcelona: Icaria.

MORA, Albert (2011). «La participación social y política como instrumento de integración: Una aproximación al asociacionismo inmigrante en España y en la Comunidad Valenciana». En: AÑón, M. José; Solanes, Ángeles y De LuCAS, Javier (eds.). Construyendo sociedades multiculturales: Espacio público y derechos. Valencia: Tirant lo Blanch.

MorAes, Natalia; BERMúdeZ, Anastasia y EsCrIVÁ, Ángeles (2013). «Las asociaciones de migrantes latinoamericanos en España como actores políticos en espacios locales y transnacionales». En: RAYA, Enrique; EsPADAS, M. Ángeles y ABOUSSI, Mourad (coords.). Inmigración y ciudadanía activa. Barcelona: Icaria.

Morell, Antonio (2005). «El papel de las asociaciones de inmigrantes en la sociedad de acogida: Cuestiones teóricas y evidencia empírica». Migraciones, 17, 111-142.

MoyA, Jose C. (2005). «Immigrants and Associations: A Global and Historical Perspective». Journal of Ethnic and Migration Studies, 31(5), 833-864. <https://doi.org/10.1080/13691830500178147>

OcA, Luzia (2015). «De Cabo Verde a Galicia: Trabajo en la pesca y transformación de las relaciones de género en contexto migratorio». Revue Internationale d'Etnographie, 5, 90-103. 
Oso, Laura; Golías, Montse y Villares, María (2008). «Inmigrantes extranjeros y retornados en Galicia: La construcción del puente transnacional». Politica y Sociedad, 45(1), 103-117.

Oso, Laura y MARTínEZ, Raquel (2018). «Gendered Mobility Strategies, Labor Market in a Context of Economic Crisis in Galicia». En: DePalma, Renée y PérezCARAmÉS, Antía (eds.). Beyond Global Cities: A Case Study of Emerging Superdiversity. Nueva York: Springer.

<https://doi.org/10.1007/978-3-319-66305-0_13>

REHER, David; REQUENA, Miguel y SANZ, Alberto (2011). «¿España en la encrucijada?: Consideraciones sobre el cambio de ciclo migratorio». Revista Internacional de Sociología, 69(1), 9-44. <https://doi.org/10.3989/ris.2011.im1.385>

VÁzQUEZ Silva, Iria (2006). Asociacionismo e integración social das inmigrantes en Galicia. Xunta de Galicia. Servizo Galego de Igualdade. Manuscrito no publicado.

Vermeulen, Floris (2005). «Organisational Patterns: Surinamese and Turkish Associations in Amsterdam, 1960-1990». Journal of Ethnic and Migration Studies, 31(5): 951-973.

<https://doi.org/10.1080/13691830500177859>

ZAPATA-BARRERO, Ricard (2004). Multiculturalidad e inmigración. Madrid: Síntesis. 